\title{
Poetry and Hedonic Error in Plato's Republic
}

\author{
J. Clerk Shaw \\ Department of Philosophy, University of Tennessee, Knoxville, \\ 806 McClung Tower, Knoxville, TN 37996-0480. USA \\ jshaw15@utk.edu
}

\begin{abstract}
This paper reads Republic $583 \mathrm{~b}-608 \mathrm{~b}$ as a single, continuous line of argument. First, Socrates distinguishes real from apparent pleasure and argues that justice is more pleasant than injustice. Next, he describes how pleasures nourish the soul. This line of argument continues into the second discussion of poetry: tragic pleasures are mixed pleasures in the soul that seem greater than they are; indulging them nourishes appetite and corrupts the soul. The paper argues that Plato has a novel account of the 'paradox of tragedy', and that the Republic and Philebus contain complementary discussions of tragic and comic pleasure.
\end{abstract}

\section{Keywords}

Plato - Republic - pleasure - poetry - tragedy

\section{Introduction}

Towards the end of the Republic, Socrates critiques tragedy and imitative poetry in general (595a-6o8b). ${ }^{1}$ That passage is often found unexpected and out of place in relation to the Republic's main argument. Were it removed, Socrates would seem to:

1 In an earlier discussion of poetry, Socrates describes the musical education of the military in Kallipolis $(379 \mathrm{a}-403 \mathrm{c})$. One standard question is whether the Republic's two main treatments of poetry advance a single, coherent view. For reasons to think that they do, see Ferrari 1989 and Heath 2013, ch. 2. 
(i) argue that justice benefits us in this life intrinsically, independently of the reputation and rewards that attach to it (357a-58oc) $;^{2}$

(ii) argue that justice is intrinsically more pleasant in this life (580c-588a);

(iii) summarize the results of his arguments for the intrinsic value of justice in this life, or deliver a sort of peroration (588a-592a);

(iv) argue that the soul is immortal, so that justice's intrinsic value extends into the afterlife (6o8c-612b);

(v) return to justice its reputation and rewards within this life (612b-613e);

(vi) return to justice its post-mortem reputation and rewards (614a-621b);

(vii) exhort us to virtue and justice $(621 \mathrm{~b}-\mathrm{c})$.

That would be tidy; whence then the digression to discuss poetry between (iii) and (iv) $?^{3}$

This paper offers a new account of Socrates' critique of tragedy and its place in the sequence just sketched: it is part of his second pleasure argument. The first such argument affirms the just person's authority to say that her life is most pleasant, due to her superior experience, knowledge and arguments (58oc$583 a) .{ }^{4}$ The second explains what experience, knowledge and arguments support her authoritative claim; Socrates calls this the 'greatest and most decisive of the overthrows' $\left(5^{8} 3^{b}\right) .{ }^{5}$ I show that this crucial argument runs not just

2 'Rewards' here include only the extrinsic consequences of justice-in the first instance, consequences of having a reputation for justice. Consequences that justice produces intrinsically, by its own power, are fair game throughout the Republic. This claim is somewhat controversial, but nothing crucial turns on it for present purposes.

3 Two main explanations have been offered for the second discussion of poetry (cf. n. 1 above). First, Socrates earlier declined to discuss stories about human beings, since doing so would beg questions about justice's value (392a-c). Once his defense of justice is complete (at 588a, followed by a summary or peroration at 588a-592a), he picks up this loose end. Secondly, the metaphysics and psychology that he has developed in the interim give him the resources for a richer critique, one more integrated with his larger view. I do not deny that Socrates returns to poetry partly to discuss stories about human beings; nor do I deny that the intervening metaphysics and psychology give him the tools for a richer and more integrated critique of poetry. However, we need not appeal to these points to explain why Socrates returns to poetry at all, because the discussion makes perfectly good sense in its immediate contextor so I shall argue.

4 This argument is actually phrased in terms of the philosopher's authority to make such claims, but we have seen earlier that the philosophical or aristocratic soul is most just.

5 Why so, since it argues that justice is intrinsically more pleasant, when Socrates is meant to argue that it is more beneficial, and says that neither pleasure nor the pleasant is the good 
from $583 b-588$ a, as scholars have universally assumed, but extends all the way to 608b. That fundamentally alters our view of three key parts of the Republic: its 'most decisive' argument, its putative summary of its main results, and its critique of tragedy.

I begin by reviewing Socrates' core claims about hedonic error and real hedonic magnitudes at $583 \mathrm{~b}-585 \mathrm{e}$ (Section 2). Next, I show that most of the discussion of poetry in Book 10 argues that tragic pleasures are much smaller than they seem (Section 3). From within Socrates' framework for hedonic error, it is clear how tragic pleasures are magnified. It is less clear why we enjoy tragedy at all — why there is any pleasure there to be magnified in the first place. So, I examine several possibilities, thereby recovering Plato's answer to a problem in aesthetics: why we enjoy painful art, ${ }^{6}$ and why we (seem to) enjoy it so much. Some aspects of our experience of tragedy only feel like pleasures, but are not. However, we do take real pleasure in certain formal features of the play (its meters, rhythms and harmonies) and in admiring both the tragic hero's good qualities and his lost goods. These pleasures are then magnified by contrast with the pains of tragic pity (Section 4).

So, most of Socrates' critique of tragedy $(595 \mathrm{c}-605 \mathrm{~b})$ extends his earlier account of hedonic error and real hedonic magnitudes $(583 \mathrm{~b}-585 \mathrm{e})$, which he follows up by examining the hedonic conditions of the virtuous and vicious (586a-588a). But why does he interrupt this sequence with an image of the soul and its parts and an account of how the just person chooses and avoids activities (588a-592a)? And why does he keep discussing poetry after showing that tragic pleasures are smaller than they seem $(605 \mathrm{~b}-608 \mathrm{~b})$ ? I argue that $583 \mathrm{~b}-608 \mathrm{~b}$ entire has a thematic АвАв structure. After Socrates explains constitutive flaws in certain hedonic experiences in Book 9 (583c-588a), he examines causal problems with the same experiences-how they nourish the soul (588a-592a). He then turns to constitutive flaws in tragic pleasures $(595 \mathrm{c}-605 \mathrm{~b})$ and causal problems with the same pleasures-how they nourish the soul

(505c-d; 581e-582a, 588a)? First, this argument can help Socrates to show that justice intrinsically benefits us without requiring any commitment to hedonism: insofar as our pleasures are real, their objects are appropriate to our nature ( $585 \mathrm{~d} 11)$, good, and congenial ( $586 \mathrm{~d}-\mathrm{e})$. More importantly, it addresses the original source of the soul's corruption, hedonic error (see Shaw 2015, ch. 6; here I extend and bolster that line of reasoning).

6 This is the 'paradox of tragedy'; modern discussions usually start from Hume's 'Of Tragedy' and Feagin 1983. Horror presents a similar phenomenon (cf. Carroll 1990), which Plato also alludes to in passing $(387 \mathrm{~b})$. The general puzzle covering all such cases is sometimes called the 'paradox of painful art'. 
(6o5b-6o6b). Socrates thus offers a single, continuous line of argument, with no odd transition between Books 9 and 10 (Section 5).

Lastly, Socrates must critique imitative poetry (or do something similar) to complete his account of hedonic error. Book 9 mentions mixed pleasures in the body and mental pleasures mixed with bodily pains (583c-584c). Book 10 then examines mixed pleasures in the soul. This can be seen most easily by considering how Republic 583b-608b and Philebus 41a-51a complement each other. So, my reading offers a neat fit between the Republic and Philebus on hedonic error, especially when it comes to mixed pleasures in the soul (Section 6). ${ }^{7}$

\section{Hedonic Error and Hedonic Measurement at $583 b-588 a$}

Socrates starts by distinguishing three hedonic states: pleasure and pain, which are opposites, and a neutral state in between. ${ }^{8}$ Because pleasure and pain are opposites, they contrast with each other, and each contrasts with the neutral state. Hedonic error occurs because of these contrasts. We should consider three cases.

The first two cases occur when one confuses either removal of pain or the neutral state with pleasure. Socrates distinguishes these cases in one of his analogies. He compares pleasure, pain and the neutral state with what is above, below and in the middle (584d-e). Within the analogy, he notes two confusions. One might confuse motion from below into the middle with motion into what is above, and one might confuse standing in the middle with standing above. In either case, the confusion arises through contrast of one's motion into the middle, or contrast of one's position in the middle, with what is below. Leaving the analogy: one might feel removal of pain as a pleasure, or one might feel the neutral state as a pleasure. Both appearances occur through contrast with a pain that is either then being removed, or that one might have experienced but is free from (most obviously, when one recently felt pain but no longer does). In neither case does one experience any genuine pleasure. Call these putative pleasures 'non-pleasures'.

7 In what follows, translations of the Republic are from Reeve 2004; and of the Philebus from Frede 1993.

8 This section follows the discussion in Shaw 2015, ch. 6. I certainly do not take my reading to be fully worked out or decisively correct, but I think it should be close enough to the truth for present purposes. 
The third case occurs when contrast-effects distort the felt magnitude of a genuine pleasure. When one feels pleasure mixed with pain, the pleasure's felt magnitude exceeds its real magnitude. At first, Socrates is less explicit about this case. Within his discussion of hedonic error, he says that most bodily pleasures involve hedonic error due to contrast with pain. His phrasing seems to suggest that most bodily 'pleasures' are mere removals of pain or states of freedom from pain (584c). However, he clarifies in the second stage of his argument, where he compares real relative magnitudes of different pleasures. There, he assumes that bodily pleasures like eating and drinking have real magnitude. They partake less of being than other pleasures (they are less [pleasant]), but they do still partake of being (they are [pleasant]). Socrates sticks to this view in what follows. First, those who focus on bodily pleasures enjoy pleasures, although these are often mixed with pain and so seem larger than they are (586b). Secondly, appetitive and spirited pleasures have real magnitude (586d-e). Thus, Socrates overstates his view about bodily pleasures at first. He soon reveals that his considered view is more modest—although still quite bold. ${ }^{9}$

After discussing hedonic error, Socrates turns to real hedonic magnitudes (585a-e). First, he describes certain states as lacks; for example, hunger is a bodily lack and ignorance a psychological lack. These lacks can be filled by their proper objects, food and knowledge. He now asks which fulfillment, eating or learning, partakes more of being — to what degree they are [fulfilling]. He gives criteria for being $[\mathrm{F}]$ in general: sameness, immortality and truth. ${ }^{10}$ Plausibly, 'sameness' is stability,1 'immortality' endurance over time, and 'truth' degree of F-ness (at those times, in those respects, and for however long something is $[\mathrm{F}])$. So, fulfillments partake of being insofar as they are stably, enduringly, truly fulfilling (at those times, in those respects, and for however long they are [fulfilling]).12

9 See Section 6 below for how these three cases map onto the kinds of false pleasure discussed in the Philebus.

10 Cf. perhaps Philebus $65 \mathrm{a}-67 \mathrm{~b}$, which uses beauty, truth and measure as proxies or criteria for goodness.

11 That is, failure to undergo change-either change over time from $\mathrm{F}$ to not- $\mathrm{F}$ (in a given respect) or the 'aspect change' of being simultaneously $\mathrm{F}$ and not-F (in different respects). Cf. Irwin 1977.

12 My gloss on 'truth' might make Socrates' position sound circular-as if being F were explained in terms of true F-ness and vice versa. To avoid circularity in this case, Socrates measures the being of fulfillments by how truly appropriate to our nature and good for us their objects are. He can then depend on prior arguments about how good and appropriate 
Socrates applies these criteria to three things: what the fulfillment pertains to, the fulfillment itself and what the fulfillment comes to be in. A fulfillment comes to be in its subject - the body for eating, and the soul for learning. A fulfillment pertains to its object-food for eating, and wisdom for learning. So, fulfillments partake of being insofar as they, their subjects, and their objects partake of sameness, immortality and truth. But being filled with what is appropriate to our nature is pleasant, and food and wisdom are both appropriate to our nature. So, the real hedonic magnitudes of eating and learning will be fixed by how much they partake of being qua fulfillments with what is appropriate to us. ${ }^{13}$

In Book 9, Socrates uses this framework to argue that psychological pleasures of acquiring virtue, true belief and knowledge are greater than bodily pleasures of eating, drinking and sex. He also uses it to bolster his earlier claim that reason's own pleasures are greatest, followed by spirit's, and then appetite's (580c-583a; 586a-587b). Eating seems more pleasant than learning; if we eat while hungry, the pleasure contrasts with pain and seems larger than it is. Socrates' method of hedonic measurement is supposed to reveal the truth. For now, though, his general framework for measuring pleasures is more important than precisely how he uses it to compare pleasures of eating and learning, of reason, spirit and appetite, or of the aristocratic and tyrannical constitutions $(587 \mathrm{~b}-588 \mathrm{a}) .{ }^{14}$

Most of Book 10's critique of poetry applies this framework for measuring pleasures. That is, it measures tragic pleasures - their being qua fulfillments with

to our nature the objects of various pleasures are. This does not remove the circularity for hedonists, so hedonists cannot measure pleasures; cf. Shaw 2015, ch. 6.

13 I do not take a stand here on the exact relationship between pleasure and fulfillment in the Republic - whether they are identical, whether the former is a perception of the latter, or something else entirely.

14 Socrates moves from pleasures of the parts of the soul (58oc-583a) to pleasures of the body compared to those of the soul $(585 \mathrm{a}-\mathrm{e})$, and then back to pleasures of the parts of the soul (586a-587a). In the second of those passages, the psychological pleasures considered are taken in knowledge, true belief and virtue. This may suggest that all appetitive pleasures are bodily (cf. 586a-b), and all pleasures of the soul rational (or rational and spirited, if spirit has true beliefs). However, appetite would seem to enjoy pleasures of the soul, such as anticipating bodily pleasures (584c). This raises difficult issues in Plato's psychology that I cannot adequately address here. 
what is appropriate to us - by assessing the sameness, immortality and truth of their subjects and objects. Briefly, Socrates first argues that the generic objects of poetic experience, imitations, are inferior in sameness, truth and being; he pursues this general point by using painting as an example (595c-598d). ${ }^{15}$ Tragedic imitations in particular are inferior in the same ways (598d-6o2b). ${ }^{16}$ Next, he turns to the subject side: imitation in general addresses an inferior part of the soul $(602 \mathrm{c}-603 \mathrm{~b})$. So does tragedy in particular $(603 \mathrm{~b}-605 \mathrm{~b})$. Thus, imitation in general is 'an inferior thing that consorts with another inferior thing to produce an inferior offspring' (6o3b). Tragedic imitation in particular 'produces work that is inferior with respect to truth and that appeals to a part of the soul that is similarly inferior' (605a). The 'inferior offspring' of an imitation and the imitation-susceptible part of the soul is an imitative experience that has the latter as subject and the former as object. But this experience is a pleasure. Thus, the argument up to this point measures tragic pleasures by assessing their subjects and objects on the dimensions described above. To defend this interpretation, I now examine in somewhat more detail the parts of the passage just sketched $(595 \mathrm{c}-605 \mathrm{~b}) .{ }^{17}$

Socrates argues that the generic objects of poetic experience, imitations, are inferior to other objects. The form of the couch is made by god; the form differs from the many couches made by carpenters, and these from painted imitations of couches. ${ }^{18}$ The second and third of these successively fall away from the form in truth and being. So painters, and imitators in general, are 'third from king and truth' (595c-597e). Furthermore, the painter imitates the carpenter's couch as it seems, not as it is. But the ways that a couch seems are variablethey do not stay the same. So, the painter imitates an illusion ( $\varphi \alpha v \tau \alpha \dot{\sigma} \mu \alpha \tau \sigma \varsigma)$ and achieves only a phantom $(\varepsilon i \delta \omega \lambda\rangle v)$, putting her kind of imitation still

15 Cf. Nehamas 1982 on possible disanalogies between poetry and painting. However, notice that Socrates does place limits on visual imitation earlier (400e-401d). In Section 5 below, I return to the talk of nourishment there, and especially its juxtaposition with talk of pleasure at $401 \mathrm{e}(\chi \alpha i \rho \omega \nu, \tau \rho \dot{\varepsilon} \varphi \circ \iota \tau 0)$.

16 This passage primarily discusses Homer, but throughout Book 10 Socrates treats Homer as the foremost of the tragedians (cf. esp. 595c, 605c-d, and 6o6e-607a).

17 Scholars often distinguish a metaphysical and a psychological argument here, and try to explain how they fit together (e.g. Moss 2007). On my reading, the discussion of metaphysics and most of the discussion of psychology compose a single pleasure argument. The end of the 'psychological argument' (esp. 605b-6o6c) really introduces a new argument distinct from (though related to) the initial pleasure argument.

18 Socrates also uses reflections of couches in mirrors as an example; this probably is meant to underline that one needs no knowledge to produce the relevant sorts of imitations (see further below). 
further from the truth (598a-b). (This already echoes Socrates' account of real hedonic magnitudes. An oligarch's pleasure is 'at a third remove from the king'; the tyrant stands at an additional third remove from the oligarch, and so has only 'a phantasm [ $[\dot{\delta} \delta \omega \dot{\omega} \lambda \omega]$ of pleasure that, as regards truth, is at a third remove from that other' $\left.\left[5^{87} \mathrm{c}-\mathrm{d}\right].\right)$

A carpenter's ability to make a couch stems from knowledge. A painter's ability to imitate the appearance of a couch (or anything else) requires no knowledge. Socrates uses this connection between one's epistemic achievements and the being, truth, and samenesss of one's products as he turns from imitation in general (using painters as his star example) to tragedic imitation specifically. Painters use shapes and colors to imitate the appearance of any artifact or living thing without needing knowledge of what they imitate; poets do the same thing with sounds. But painters and poets both seem to the ignorant to know every craft. The reason is that they make (seemingly) beautiful imitations that appear to be of the sort that someone with knowledge would make (598b-599a). ${ }^{19}$ Socrates does not want to just assume that poets lack knowledge of what they imitate, though; rather, he argues that they lack knowledge (599a-6o1c) — and indeed, that they lack even true belief (601c-602a). This shows that imitative poetry, like painting, imitates things as they seem, not as they are.

Socrates is especially concerned with how tragedy imitates virtue. So he focuses his attention on politics and education, which aim to make people virtuous, and he argues that poets lack both knowledge and true belief about virtue. If someone could make either virtuous people or images of virtuous people, they would of course choose to make the former. But poets manifest no ability to make anyone virtuous, either publicly or privately. So, tragic poets lack knowledge. To show that tragic poets lack true belief as well, Socrates distinguishes someone who uses a certain artifact well from the person who makes it for her, following her directions. The maker has true belief about what she makes, flowing from the testimony of the user, who knows. But poets do not design their imitations to meet the requirements of one who knows virtue; they design their imitations to meet the expectations of the ignorant many (6o2a-b, 605a; cf. 493d, 598b-d). ${ }^{20}$ Now, if someone with knowledge or true belief about virtue made an imitation of virtue, they would imitate virtue as it is. Since tragic poets take their cues from the ignorant many, they imitate virtue as it seems. (Poets in Kallipolis will have true belief, flowing from the rulers' knowledge. So, they will imitate virtue as it is, and help to make

19 Cf. Belfiore 1983, 44-48.

20 Cf. Shaw 2015, esp. ch. 5. For related comments on true belief, see Shaw 2011, Section 3. 
the citizens virtuous, in a subordinate way.) Thus tragedians, like other imitators, produce things far from the truth (6oza-b) ${ }^{21}$ (Notice here another echo from earlier: Socrates says that tragedians lack true belief and knowledge of what they imitate, especially virtue. So, they cannot transmit to the audience any true belief, knowledge or virtue - the objects of pleasures of the soul discussed before, at $585^{b}$-c.)

Socrates turns next to the part of the soul affected by imitation in general. He first distinguishes an imitation-susceptible part of the soul from the rational part that measures and calculates, and so can resist imitative appearances. ${ }^{22}$ Imitative appearances conflict with those delivered by calculation and measurement, so they must affect a distinct, inferior part of the soul (6o2c-6o3b). ${ }^{23}$ The same applies to imitative poetry, which imitates 'human beings acting under compulsion or voluntarily, who, as a result of these actions, believe they are doing either well or badly, and so experience either pain or enjoyment in all these situations' (603c); tragedy surely imitates those who believe they do badly and so feel pain. Socrates now says more about the original that tragedy imitates: when we face misfortune, reason wants to deliberate about how to organize our affairs for the best in the light of that misfortune, but another, inferior part wants to lament. Because tragedy imitates those who face misfortune, it imitates people who face this psychological conflict. But it is easier to imitate someone who laments than someone who calculates and quietly goes about her life, and the former sort of person is also more familiar to the audience. (Someone ruled by the part that longs to lament admits of 'complex imitation'. This suggests that (i) the resulting imitation does poorly on the dimension of 'sameness', and (ii) whenever that part of the soul is the subject of a pleasure, it does poorly on the same dimension.) Both because it is easier and because it appeals to their audience, tragic poets imitate the appearance of one who laments, and they present such imitations to the parts of us that enjoy such things - those inferior, variable parts that want to lament when we face our own misfortunes $(603 \mathrm{~b}-605 \mathrm{~b})$.

21 Socrates does not yet directly address the sameness of tragedic imitations, but he will soon; see below.

22 This part seems to be characterized in terms of its susceptibility to visual appearances (including visual illusions) which may seem to overlap with imitations only in part. Here it is crucial that the imitations in question are imitations of things as they appear.

23 Some read Socrates' description of visual illusion and measurement (602c-6o3a) as requiring a division within reason (e.g. Nehamas 1982). However, Adam 1902, 466-7 provides a way to read the crucial sentence at $602 \mathrm{e}$ without positing such a division, which seems preferable. 
Thus, imitations in general are inferior in sameness, truth and being (595c-598d). ${ }^{24}$ Imitation presents its inferior products to an inferior part of the soul (6o2c-6o3b); together these produce an 'inferior offspring' (6o3b). Tragic poetry follows the pattern: its products are inferior (598d-6o2b), and it presents its inferior products to an inferior part of the soul $(603 \mathrm{~b}-605 \mathrm{~b} ; 605 \mathrm{a}$ brings these two points together). Again, the 'inferior offspring' is the imitative experience. But the imitative experience is pleasure. ${ }^{25}$ Tragedy aims to please and gratify the inferior part $(605 \mathrm{a}, 605 \mathrm{c})$; we enjoy watching the hero lament $(605 \mathrm{~d})$, the poets give satisfaction and enjoyment to the appetite for lamentation (6o6a); we thus enjoy other people's sufferings, and consider that pleasure a profit (6o6b); allowing poetry into the city lets pleasure and pain rule there (607a); imitative poetry aims at pleasure, and we are charmed by it (607c). The bulk of Socrates' argument against tragedy $(595 \mathrm{c}-605 \mathrm{~b})$ thus uses his earlier framework for measuring a pleasure's true magnitude by evaluating its subject and object. The subject and object of tragic pleasure are both inferior in the relevant ways, so the real magnitude of tragic pleasure is small—much smaller than it seems. ${ }^{26}$

\section{Hedonic Error at 595c-6o5b and the Paradox of Tragedy}

Book 9 offers a simple explanation for why tragic pleasure seems larger than it is: juxtaposition with tragic pity, which is painful, is internal to its nature. Socrates' general account of hedonic error predicts that such pleasures will seem larger than they are. This offers a partial solution to the paradox of tragedy, but a full solution must answer another question as well: what is the basic pleasure magnified through contrast with tragic pity?27

24 What about immortality? Right after the discussion of poetry, Socrates argues that the soul, or perhaps reason alone, survives death $(608 \mathrm{c}-612 \mathrm{~b})$. However, this argument helps to establish not only the true size of our pleasures, but also the true extent to which justice benefits; hence its location. Cf. n. 54 below.

25 At Tht. 156a-157c, Socrates describes a theory of perception on which slow changers (e.g., an eye and a stone) jointly produce joint fast-changing offspring (e.g., sight and whiteness). Among the fast-changing offspring on the subject-side are pleasures and pains (156b). The Republic's treatment of pleasure seems to suggest a single offspring of the imitation and the imitation-susceptible part, not twin offspring.

26 Belfiore 1983 assumes that pleasure as such deceives, which I deny.

27 For other proposed solutions to the paradox of tragedy, none of which captures Plato's, see Smuts 2009. 
There are several possibilities. First, I will consider whether the 'pleasures' of tragedy might all be non-pleasures - removals of pain or states of freedom from pain that only feel like pleasures. Secondly, I will consider pleasures taken in the poem's formal features-its meter, rhythm and harmony. Thirdly, I will consider the idea that we take pleasure in lamentation as such, and analyze the relationship between lamentation and grief to come to a better understanding of such pleasure. Finally, I will consider whether admiring the character of the tragic hero involves some genuine pleasure.

It is plausible to think that our experience of tragedy involves some nonpleasures. Watching another endure misfortune can make us aware that we are free from the pain they feel. By contrast with their pain, we then feel our own freedom from pain as if it were pleasure. Indeed the Epicureans, who consider such experiences genuine pleasures, endorse this as a strategy for inducing joy in oneself (Lucretius, De rerum natura 2.1-19; Plutarch, Non posse 1091B; Cicero, De finibus 1.62). But Socrates certainly cannot think that this non-pleasure exhausts our hedonic experience of tragedy, for he thinks we also enjoy lamenting our own misfortunes. We cannot then 'enjoy' our freedom from pain by contrast with another's pain; the pain in question is our own. And more generally, it seems implausible to assume that all tragic 'pleasures' will be mere nonpleasures. Socrates says repeatedly that tragedy pleases us (cf. Section 3 above, last paragraph). True, he sometimes talks casually about non-pleasures as if they were real pleasures. But if he were doing that systematically with tragic pleasures, we would expect him to call them 'so-called pleasures' or something similar, at least once. So, while our experience of tragedy involves the nonpleasures just mentioned (and more, as we shall see), a full inquiry should unearth some genuine pleasures in tragedic imitations and real-life misfortunes.

It is plausible to suppose that we enjoy the poem's formal features-its meter, rhythm and harmony. For, when these features are removed, poetry 'resemble[s] the faces of those who are young but not really beautiful, after the bloom of youth has left them' (6orb). ${ }^{28}$ This hypothesis is bolstered by Socrates' claim that poetry is audible imitation, as painting is visible imitation $(603 \mathrm{~b}){ }^{29}$

28 6o1a-b stresses the role of meter, rhythm and harmony in making people think one speaks well. Cf. Gorgias 502c, which might seem to assume that much rhetoric is devoid of meter, rhythm and harmony, even though it is a sort of flattery (i.e. a practice aimed at pleasure). However, Socrates' main aim there is to identify poetry as a kind of rhetoric, not to mark off rhetoric as devoid of all meter and rhythm.

29 Cf. Socrates' discussion of pleasure taken in simple colors, shapes, sounds and smells at Philebus 51b-e. It is unclear to me exactly how pleasure in such cases is related to the perception of (for example) green. 
It may also help to explain why he limits the meters, rhythms and harmonies allowed in the city, and especially why he bans the modes suitable for dirges and lamentations and those mixed meters and polyharmonic instruments that can produce large felt pleasures through contrast effects (398b-40oe). ${ }^{30} \mathrm{But}$ while meter, rhythm and harmony are clearly relevant to our hedonic experience of tragedy, they cannot provide all of the relevant pleasure. Here again, the comparison with actual misfortune is instructive. Socrates thinks there is some single kind of pleasure felt in watching the hero lament in tragic imitations, in watching another lament actual misfortune, and in lamenting one's own actual misfortune. The last two cases rarely involve meters, rhythms and harmonies that could provide much pleasure.

Another possibility is that we take pleasure in lamentation (whose relationship to grief and pity must then be explored). ${ }^{31}$ After all, Socrates says we have a natural appetite for lamentation: 'what is forcibly kept in check in our personal misfortunes and has an insatiable hunger for weeping and lamenting — since that is what it has a natural appetite for - is the very factor that gets satisfaction and enjoyment from the poets' (6o6a). When this appetite is fulfilled by lamenting, we feel the pleasure of appetite-satisfaction. On this view, grief might simply be an appetite for lamentation, which lamenting satisfies, thereby removing the pain of grief. But then, lamentation would seem to be the mere non-pleasure of removing a painful desire, like scratching an itch.

Someone might reply: desires we can eliminate by practicing from childhood are unnecessary, but those we cannot deny are necessary (558d-559c); grief cannot be eliminated (603e); so, if grief is a desire for lamentation, we have a necessary desire to lament, and fulfilling such desires gives us real pleasure. This last step is too hasty, though. Necessary desires are either ineliminable or beneficial. Again, compare scratching an itch: we cannot eliminate itches and desires to scratch, so this is a necessary desire. So, when an appetite is necessary because it is ineliminable, satisfying that appetite may provide no real pleasure, but only the apparent pleasure of removing pain.

Perhaps we should rethink the relationship between grief and lamentation. Grief is not a bare appetite for lamentation, but pain felt at losing some specific good. When one's child dies, for example, one inevitably feels the lack of that child and grieves her loss. One response to the loss of a good is to try to fill the resulting lack— to retrieve lost goods or find replacement goods. Fulfilling

30 NB any genuine pleasure taken in formal features of tragedy probably will not float free of content. I thank Rachana Kamtekar for pressing me on this point.

31 Discussions with Sarah Jansen helped me to develop the next four paragraphs. 
a felt lack involves some genuine pleasure, though magnified by contrast with antecedent pains. But some lost goods cannot be retrieved or replaced, as when one's child dies. ${ }^{32}$ In such cases grief - pain at an irretrievably lost and irreplaceable good-is inevitable. Pleasures of lamentation can then be connected to grief in at least two ways. First, grief manifests in the body as tension. Crying removes the tension, so it feels pleasant. ${ }^{33}$ However, this is another non-pleasure, another mere removal of pain. Secondly, lamentation seems directed at an intentional object, the same thing one grieves the loss of. So, lamentation may be pleasant because it involves recalling the goodness of what one has lost (cf. Aristotle, Rhetoric 1.11, 1370b25-8). Here at last we find one source of genuine pleasure in lamentation.

Plausibly, pity and lamentation share a similar relationship. If pity is another bare desire to lament, then the pleasures of lamentation would seem to be mere non-pleasures. Likewise the felt bodily pleasures of crying, which removes bodily tension built up by seeing another suffer. But lamentation at another person's loss, whether real or imitative, involves taking real pleasure in thinking about the goodness of what they have lost. Such pleasures may be more intense in one's own case, but they are there in relation to others' lost goods as well.

A final possibility departs from the events tragedy imitates. Again, imitative poetry generally portrays 'human beings acting under compulsion or voluntarily, who, as a result of these actions, believe they are doing either well or badly, and so experience either pain or enjoyment' (6o3c). Tragedy specifically imitates a good person experiencing misfortune, believing he is doing badly (and so grieving), and lamenting. The crucial point is that the tragic hero is portrayed as good (his reaction to misfortune aside; see below). ${ }^{34}$ This is clearest when Socrates says we 'praise and pity' him ( as the hero has good features, we enjoy admiring him. ${ }^{35}$ This also explains some pleasure we take in lamenting our own misfortunes. We think those misfortunes are unfitting, because we are good; our self-admiration provides

32 Contrast Vlastos 1973, whose claims I cannot address here.

33 Jansen 2015 emphasizes the physical pleasures of crying. Notice that this could relate our appetite for lamentation to the body (cf. n. 14 above).

34 Were they not portrayed as good, the result could end up being closer to comedy-which also produces mixed pleasures, but with a different structure. I say a bit more to compare comic and tragic pleasures in Section 6 below.

35 There is an open question about the relationship between seeing the hero as admirable and the pleasure we take in so seeing them (or ourselves; see below). Cf. n. 29 above on visual pleasure and color-perception. 
real pleasure magnified by contrast with grief. Of course, there are complications. Because the tragic hero grieves excessively and laments, Socrates says he has 'purported goodness' (6o6b). Nonetheless, he is still portrayed as having good features, we still admire those good features, however inconsistent with his reaction, and that still gives us some real pleasure. ${ }^{36}$ However, some tragic pleasure may stem from seeing the 'good person' react as we are ashamed to react to our own misfortunes. ${ }^{37}$ To that extent, we feel mere non-pleasure-a removal of shame-or perhaps a renewed sense of our own (putative) goodness, despite the counterevidence provided by our lamentations.

In short, then, the basic real pleasure we take in tragedy is some combination of (a) pleasure in meters, rhythms and harmonies, (b) pleasure in recalling the lost good, and (c) pleasure in admiring the hero's good qualities. ${ }^{38}$ In real-life pity and grief, (a) falls out and we are left with a combination of (b) and (c). In all cases, juxtaposition of these pleasures with pains of pity or grief makes the pleasure seem greater. ${ }^{39}$ And, of course, our experience of tragedy also involves many non-pleasures, which increase our felt pleasure still further.

36 There may be a disanalogy here; perhaps the tragedian can depict an impossible object, the good person who laments, that we cannot instantiate. (Here it is important that tragedy imitates the good person as he seems to the many, not as he is.) If so, then, when we grieve intensely and lament, we cannot take genuine pleasure in our own goodness, as we can in the depicted goodness of the tragic hero. A fuller reckoning would have to reflect the fact that most people are good in some ways and bad in others.

37 Compare the 'pleasure' of watching others cry and lament in court, when one has done so oneself in the past (Apology $38 \mathrm{~d}$ taken with $34 \mathrm{~b}-\mathrm{d}$ ).

38 These pleasures are preserved in the hymns and encomia retained in the city, but without the complex meters, rhythms and harmonies that involve hedonic error due to contrast effects. Spirit likely houses the pleasures of admiring good qualities; appetite may house pleasures taken in rhythm, meter, and harmony. (These are perceptual pleasures, and appetite and perception both have some kind of special connection to the body.) Pity and grief are likely appetitive pains, since spirit and reason both resist the desire to lament (6o3e-604a).

39 In unpublished work, Sarah Jansen argues that the analogues to skiagraphia in tragedy are contrasts of mixed character that accent the good and those of mixed fortune that accent the bad. In support of this view, she notes that Socrates' only example of ethical measurement is a measurement of good and bad (6o4b-c). We can agree that Socrates is concerned with contrasts of both pleasure and pain and those of good and bad and virtue and vice, even if we end up disagreeing about how these contrasts are related to each other and which are most central to Socrates' critique of poetry. 
Thus, most of Socrates' Book-10 critique of tragedic imitation uses his framework for hedonic measurement to show that our experience of tragedy is less pleasant than it seems. In particular, tragedy cannot fill us with such truly pleasant objects as virtue, knowledge and true belief, but only with images of how those things seem. However, this leaves two passages out of the account. The first is 588a-592a, which separates the two discussions of hedonic measurement and error, thus obscuring their connection. There, Socrates gives an image of relations among the parts of just and unjust souls and describes

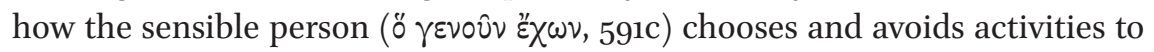
develop and maintain a just, healthy constitution. The second is $605 \mathrm{~b}-608 \mathrm{~b}$, which continues the discussion of tragedy and poetic imitation in general. Earlier, I said these are B-passages in an АBAB thematic structure. The A-passages critique certain felt pleasures constitutively; the B-passages show how those felt pleasures nourish the soul, and so corrupt or improve its constitution. To support these claims, I now take a step back and look at the first B-passage in its context.

After Socrates gives an account of hedonic error (583b-585a) and explains how to measure the real magnitudes of pleasures ( $585^{\mathrm{a}-\mathrm{e})}$, he describes the hedonic conditions of the virtuous and vicious. Not only are reason's pleasures greater than those of spirit and appetite, but when reason rules-when it decides what satisfactions and pleasures spirit and appetite receive- they too get the most pleasure possible for them (585e-588a). Especially important for seeing the connection between $583 \mathrm{~b}-588 \mathrm{a}$ and $588 \mathrm{a}-592 \mathrm{a}$ is this passage (586d-587a):

Can't we confidently assert, then, that, even where the desires of the profit-loving and honor-loving parts are concerned, those that follow knowledge and argument, and pursue with their help the pleasures that wisdom prescribes, will attain - to the degree that they can attain true pleasure at all - the truest pleasures, because they follow truth, and those that are most their own; if, indeed, what is the best for each thing is also what is most its own?... So, when the entire soul follows the philosophic element and does not engage in faction, the result is that each element does its own work and is just; and, in particular, each enjoys its own pleasures, the best pleasures and — to the degree possible — the truest.

Socrates continues this line of thought with an image of the relations among our soul-parts: by indiscriminately feeding spirit or appetite we starve reason; 
it is better for reason to rule and decide when and how spirit and appetite are nourished (588b-589c). ${ }^{40} \mathrm{He}$ makes this point with a range of terms: feast-

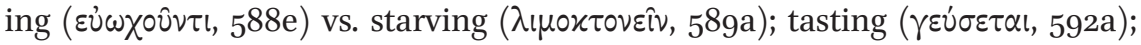

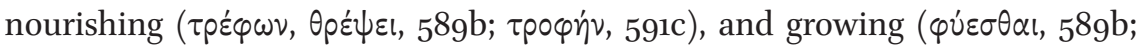
$\alpha \ddot{\xi} \xi \eta \tau \alpha \mathrm{l}, 590 \mathrm{~b})$. He uses relatively little pleasure terminology, ${ }^{41}$ but the words above are clearly associated with pleasure. We can see the connection in three ways. First, Socrates says a bit earlier that being filled with what is appropriate to our nature is pleasant $(585 \mathrm{~d}-\mathrm{e})$. Talk of fulfillment ( $\pi \lambda \dot{\eta} \rho \omega \sigma \iota \varsigma)$ evokes eating and drinking (LSJ s.v. I.2) and so connects pleasure to feasting and nourishing. Secondly, much earlier Socrates describes how the guardians are educated by their physical surroundings (401b-402a). He compares the guardians to grazing animals and their surroundings to grass (401b-c). This effectively calls education psychological nourishment. He then connects these with pleasure: because someone trained properly 'feels distaste ( $\delta v \sigma \chi \varepsilon p \alpha i v \omega v)$ correctly, he will praise fine things, be pleased ( $\chi \alpha i p \omega \nu$ ) by them, take them into his soul, and,

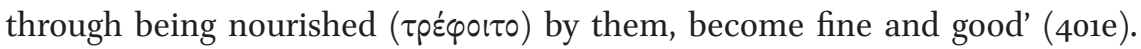
(Notice the connection between taking fine things into the soul and the fulfillment model of pleasure.) Finally, Socrates connects pleasure and nourishment in the second B-section. There, he uses a narrower range of terms to talk about how pleasures affect the soul than he did in the first B-section-he says

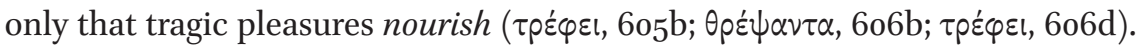
However, he consistently uses pleasure vocabulary there (cf. again Section 3 above, last paragraph). This makes it clear that pleasure, or perhaps pleasure's object, nourishes the soul.

So, at the end of Book 9, it is reasonable to think that Socrates describes how our choices and avoidances of pleasures and pains shape our souls, and that this continues a theme introduced earlier (esp. 586d-587a). Specifically, the sensible person will neither act unjustly (591a; cf. 588b, 588e) nor avoid punishment for injustice (591a-b). The goal of letting reason rule guides her choices and avoidances of all pleasant objects, including studies (591b-c), bodily health (591c-d), money (591d-e), honors (591e-592a) and so too political activities, which after all concern honors (592a-b).

40 Socrates also argues that this fact about the soul is the source of conventions about virtue; 589c-591a.

41 Socrates does say that appetite is insatiable $(\dot{\alpha} \pi \lambda \eta \sigma \tau i \alpha \varsigma)$, evoking pleasure as a fulfillment ( $\pi \lambda \dot{n} \rho \omega \sigma \iota)$, and that the sensible person avoids 'brutish and irrational pleasure' $(\tau \hat{\eta}$

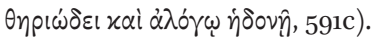


That is the end of Book 9, as the work is usually divided. ${ }^{42}$ Few question the break, since Socrates' return to poetry seems intrusive. ${ }^{43}$ But in fact, the argument flows smoothly. As the sensible person chooses and avoids pleasures and pains so as to let reason rule when it comes to justice, punishment, studies, health, money, honors and politics, so she chooses and avoids aesthetic pleasures and pains in the same way. This is clearest in the last line of Socrates' discussion of poetry: 'we must not be tempted by honor, money, or any sort of office whatever-not even poetry! - into thinking that it is worthwhile to neglect justice and the rest of virtue' (6o8b). This echoes the end of 9 and links the unhealthy nourishment provided by tragic pleasure with the like effect of other pleasures mentioned earlier.

So, the Book-9 argument has two sides: first, certain experiences are less pleasant than they seem; secondly, indulging those experiences starves reason and erodes the virtuous constitution in which reason rules, and in which each part receives both the greatest goods and the most pleasure it can. Most of Book 10's discussion of tragedy parallels the first part of Book g's argument: pleasures of poetry are smaller than they seem. But further, tragic pleasures corrupt our constitution. ${ }^{44}$ To review: in misfortune, the soul is in conflict. Reason wants to deliberate, appetite wants to lament, and spirit is ashamed to lament, at least when others are present $(603 \mathrm{e}-604 \mathrm{~d} ; 605 \mathrm{~d}-\mathrm{e})$. Tragedy imitates misfortune in the life of a good person and how she responds to it. However, it is easier to imitate someone lamenting, and that is what the many want to see, so that is what the poet imitates (604e-605a). Now, the new point: by enjoying tragedy, we feed our appetite for lamentation and destroy reason, thereby corrupting ourselves $(605 \mathrm{a}-\mathrm{c}) .{ }^{45}$ Indeed, this happens even to decent people.

42 Here it is worth remembering that our ten-book division of the Republic likely postdates a six-book division that may go back to Plato himself. For discussion, see Sedley 2013, 70-4 (but notice that Sedley, like most scholars, sees a natural break between Books 9 and 10 of the 10-book division). I thank David Ebrey for bringing this point to my attention.

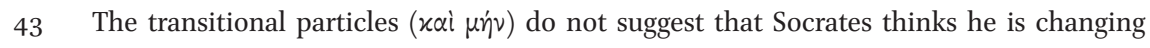
topics completely. Cf. $\dot{\alpha} \lambda \dot{\alpha} \mu \dot{\eta} \nu \ldots \gamma \varepsilon$ for the transition to how the sensible person chooses and avoids honors (592a).

44 Annas 1982 worries about how Plato can simultaneously denigrate poetry as trivial and as dangerous; my reading removes her worry. Poetry offers small but dangerous pleasures.

45 An anonymous referee notes that Socrates marks a transition to his 'chief charge' at $605 \mathrm{c}$, and suggests that this militates in favor of my contention that $583 \mathrm{~b}-608 \mathrm{~b}$ has an АВАВ structure. I hesitate, though, because Socrates has already introduced the theme of nourishment in 605b ('he arouses and nourishes this element in the soul and, by making it strong, destroys the rational one'). So, on my account, the transition to the B theme precedes any talk about the 'chief charge'. Rather, 605c seems to move from how tragedy 
Decent people are those whose shame at lamenting and desire to deliberate usually rule their appetite to lament, when they suffer misfortune. ${ }^{46}$ If these people have not been adequately educated, though, they think their enjoyment of tragedy is a 'clear profit'. They have not calculated that when they pity tragic heroes and lament along with them, their appetite to lament grows stronger and more likely to rule their other, better desires when they encounter misfortune in their own lives (6o5c-6o6b).

My reading of 588b-592a faces several objections. At the beginning, Socrates says we should return to the original problem and address our challenger, and he reverts to the language of profit ( $\lambda \nu \sigma \tau \varepsilon \varepsilon \lambda \varepsilon i v)$ prominent in Books 1-2. He says they have agreed what powers doing justice and injustice have, whereas my reading may seem to predict that we are not quite done describing their powers. Finally, Socrates refocuses on the city-soul analogy and the roles of law and reason in the city and soul. That suggests a summary that returns to earlier themes, not a continuation of the immediately preceding argument. ${ }^{47}$

However, all these features are fully consistent with my reading, on which Socrates turns from constitutive problems with certain pleasures to how pleasant activities nourish the soul. That is precisely a question of whether the pleasant activities in question profit us. Notice too that the language of profit recurs at the end of the poetry argument in Book 10. Socrates locates the insidiousness of tragic pleasure in its seeming to offer a hedonic profit without cost-unless one calculates how it corrupts the soul (6o6b). Nor is it peculiar to return to the original challenger while offering the argument that most decisively refutes him. Nothing about reverting to the city-soul analogy or the importance of reason and law shows that Socrates has left behind the effects of our pleasures to sum up his whole defense of justice. Even in earlier parts of the pleasure argument, Socrates connects psychology and politics (586a-b) and stresses the importance of law and reason in satisfying the whole soul (586d-588a; for law, see $587 \mathrm{a}$ and $587 \mathrm{c}$ ). The same passages show how Socrates

nourishes souls in general to how it nourishes 'the best among us'. (The anonymous referee also suggests that 'the best among us' who can be harmed by poetry must include even those who have been adequately educated. I want to leave room for the possibility that Socrates thinks even 'the best among us' have not been adequately educated, because of how cities are currently organized. Socrates himself may be an exception, though, not least because he has performed the requisite calculation.)

46 Belfiore 1983 claims that most of us are 'decent' in Plato's sense, but I doubt Plato would agree.

I thank Julia Annas for pressing these points. 
has already gained agreement about the powers of doing justice or injustice. On any plausible reading, 588a-592a does not just repeat what he has already said, but develops previous agreements. Socrates has already alluded to how our choice of pleasures shapes our constitution (586d-587a); 588a-592a further articulates how we should choose pleasures in light of that fact, and says it more vividly, using a provocative and memorable image.

The Philebus and How Republic 1o Completes Republic 9

One might grant that $595 \mathrm{a}-608 \mathrm{~b}$ continues Socrates' argument about pleasure and the soul's nourishment at $583 \mathrm{a}-592 \mathrm{~b}$, but deny that the poetry passage is needed in the final pleasure argument. Perhaps Socrates must discuss poetry again (for standard reasons) and simply integrates that discussion with his pleasure argument. In contrast, I maintain that Socrates' discussion of poetry (or something relevantly similar) is necessary to complete his pleasure argument. That can be seen most readily by comparing discussions of hedonic error in the Republic and Philebus.

The hedonic errors described in the Republic map onto three of the four kinds of false pleasure discussed in the Philebus. The Republic says that pleasures often seem larger than they are, and experiences that are not pleasures often seem like pleasure, due to contrast-effects. The four kinds of false pleasure in the Philebus are: 'false anticipatory pleasures' (38b-41a); false pleasures of overestimation (41a-42c); removals of pain or states of freedom from pain that seem like pleasures (42c-44b); and-after a discussion of certain natural scientists who say that all 'pleasures' are mere removals of pain-mixed pleasures (46b-51a). The third kind of false pleasure covers the same territory as 'non-pleasures' in the Republic (as I called them earlier). ${ }^{48}$ The Philebus' second and fourth kinds of false pleasure-false pleasures of overestimation and mixed pleasures - are two sides of the same coin. Together, these cover the

48 The natural scientists discussed in the transition from non-pleasures to mixed pleasures (44b-46b), who say all pleasures are non-pleasures, start from intense pleasures felt in pathological conditions, argue that those are non-pleasures, and then extend their analysis. The end of the transition calls mixed pleasures 'the whole tribe of such pleasures' (46b), so Socrates may seem to say that mixed pleasures are really non-pleasures. But he disagrees with the scientists here, although he uses them as witnesses to the existence of non-pleasures (51a). (Some may doubt that Socrates accepts non-pleasures as part of his account of false pleasure in the Philebus, since he says false pleasure is still pleasure: $37 \mathrm{~b}$. But this says that whatever takes pleasure cannot be deprived of taking pleasure; one who experiences non-pleasure does not take pleasure.) 
same territory as the Republic's genuine pleasures that seem larger than they are due to juxtaposition with pain-as I now argue.

The Philebus introduces false pleasures of overestimation like this: 'because [pleasures and pains] are alternately looked at from close up or far away, or simultaneously put side by side... pleasures seem greater compared to pain and more intensive, and pains seem, on the contrary, moderate in comparison with pleasures' (42b). ${ }^{49}$ However: 'if you take that portion of them by which they appear greater or smaller than they really are, and cut it off from each of them as a mere appearance and without real being, you will neither admit that this appearance is right nor dare to say that anything connected with this portion of pleasure or pain is right and true' (42b-c). Right from the start, then, Socrates ties false pleasures of overestimation to mixed pleasures, and he points to mixture as the cause of overestimation. These passages parallel Republic 9, which describes hedonic errors due to juxtaposition of pleasures and pains (583b-585a) and then gives an account of real hedonic magnitudes - the being

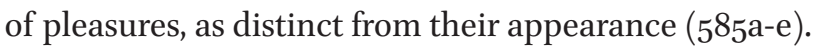

His discussion of mixed pleasures in the Philebus likewise emphasizes their great felt magnitude. This theme begins in the transition to the topic of mixed pleasures, since the scientists start by looking at our most intense pleasures (44d-45e); it continues in the discussion of mixed pleasures in the body, which emphasizes the great apparent size of such pleasures (47a-b); finally, it returns in Socrates' final thoughts about false pleasure, where he distances himself from the scientists by separating 'kinds that only seem to be pleasures, but are not so in reality' from 'others that have the appearance of enormous size and great variety, but which are in truth commingled with pain or with respite from severe pains' (51a-b). Once more, then, mixed pleasures and false pleasures of overestimation are one and the same, and overestimation is caused by mixture with pain. Together, these map onto the Republic's genuine pleasures that seem larger than they really are, due to juxtaposition and contrast with pain.

So, the Republic's account of hedonic error maps onto three kinds of false pleasure in the Philebus. ${ }^{50}$ Republic 9 describes pleasures that seem larger than

49 It is odd that juxtaposition with the opposite is supposed to intensify pleasure but moderate pain. This may reflect a larger asymmetry between good (which has positive existence) and bad (which is the mere deprivation of goodness).

5o That leaves the first kind of false pleasure in the Philebus, 'false anticipatory pleasure' (38b-41a). This is more aptly called 'false higher-order pleasure', since anticipatory pleasures are one kind of false pleasure directed at other putative pleasures in the past, present or future. Future-directed higher-order pleasures may be most common, though (4od). Socrates says explicitly how these differ from other false pleasures: false beliefs 
they are because of mixture and the limit case-conditions that seem like pleasure but are removals of pain or states of freedom from pain. Socrates there mentions mixtures of pleasure and pain within the body (cf. Phlb. $46 \mathrm{c}-47 \mathrm{c}$ ) and mixtures of pleasure in the soul with pain in the body (e.g. the pleasure of anticipating a pleasant meal while hungry; cf. Phlb. $47 \mathrm{c}-\mathrm{d}) .{ }^{51}$ But Republic 9 says nothing about mixtures of pleasures and pains within the soul, which is the third kind of mixed pleasure discussed in the Philebus (47d-5oe).

Republic 10 completes the logical space by describing mixtures of pleasure and pain within the soul in tragedy and misfortune. It also gestures at a parallel account of pleasures of comedy and real-life comedic circumstances (6o6c). This is not too surprising; after all, Socrates earlier limited artistic representations of laughter as well as lamentation (387c-389a). Socrates does not develop his claims about comedy in the Republic. In the Philebus, though, Socrates' discussion of mixed pleasures in the soul emphasizes comedy (48a$5 \mathrm{ob}$ ). Again, though, his target in that passage is not so narrow; he bookends his discussion of comedy with vague claims about mixed pleasures in tragedy and lamentation (48a, 5ob). These, of course, are the main topics of Republic 10, which (again) gestures vaguely at similar claims about comedy. Further, in the Republic a key part of our genuine pleasure in tragedy comes from admiring the tragic hero's goodness. The pain that sets that pleasure in relief and increases its felt magnitude comes from watching the hero suffer and grieve. The account of comedic mixed pleasure in the Philebus reverses this analysis. There, the pain involved is malice toward someone self-ignorant, and the pleasure comes from seeing her get her comeuppance-in central cases, at least, precisely because of her self-ignorance. ${ }^{52}$

about pleasure cause false higher-order pleasures, but false pleasures of overestimation cause false beliefs about pleasure (42a; notice that $R .5^{8} 4 \mathrm{e}-585$ a distinguishes misleading hedonic experiences from false beliefs about those experiences). False first-order pleasures are strictly prior in the order of explanation, followed by false beliefs about pleasure and then false higher-order pleasures_-although these last are first in order of presentation. A false higher-order pleasure could be directed at a pure pleasure-as when one anticipates smelling a rose that one never smells—but these are marginal cases at best. (In unpublished work, Emily Fletcher develops a similar view, but she would not agree with everything I say here.)

$51 \quad$ Philebus $47 \mathrm{c}-\mathrm{d}$ also refers back to $35 \mathrm{e}-36 \mathrm{c}$. NB this earlier discussion of pleasure in the soul mixed with pain in the body is what leads directly into Socrates' larger discussion of false pleasure (36c).

$5^{2}$ Comedy also requires that the self-ignorant person be powerless; self-ignorance combined with power is fearful and odious, not ridiculous. Tragedy may likewise require that the hero is powerful, so that he can be engaged in important affairs (which Aristotle 
So, the Republic and Philebus are not merely consistent with each other (at least at a certain level of abstraction); they actually complement each other's treatments of mixed pleasures within the soul. This can only be seen once we understand Socrates' second discussion of poetry as part of his third, 'greatest and most decisive' argument for the intrinsic value of justice in the soul.

\section{$7 \quad$ Conclusion}

With these new readings of Republic 588a-592a and 595a-6o8b in hand, I revisit the sequence of arguments in Books 9-10. Socrates gives three arguments for his main thesis in the Republic. The first ends at $580 \mathrm{c}$, and the second is at $580 \mathrm{c}-583 \mathrm{a}$. The third stretches all the way from $583 \mathrm{~b}-608 \mathrm{~b}$; it examines hedonic error, real hedonic magnitudes, and how our choices of pleasures and pains affect our psychological constitution. Socrates starts with a general account of hedonic error due to contrast effects $(583 \mathrm{~b}-585 \mathrm{a})$, in which he mentions mixed pleasures within the body and between body and soul (584c), but leaves out mixed pleasures in the soul. He then explains how to measure true magnitudes of pleasure, and argues that the soul's pleasures are greater than the body's $(585 \mathrm{a}-\mathrm{e})$, that reason's pleasures are greater than spirit's and appetite's, and that spirit and appetite get the most pleasure when reason controls their satisfactions and pleasures (586a-587a). In light of that, he argues that the aristocrat, who is most just, lives 729 times more pleasantly than the tyrant, who is least just (587a-588a). He then offers an image of the tripartite soul, for purposes of describing further how our choices and avoidances of pleasures and pains affect the soul's constitution (588a-592a).

Socrates' return to the topic of poetry continues the same line of argument. First, he uses his account of hedonic measurement to critique tragic pleasures by examining their objects (598d-6o2c), their subjects $(603 \mathrm{~b}-605 \mathrm{~b})$, and so their offspring, the pleasures (6o3b). (He proceeds throughout by reference to features of imitation generally and to painting in particular as a case of imitation.) Then, he describes how the pleasures of tragedy affect the soul's constitution (605a-6o6b). After gesturing at similar views of both comedy (6o6c) and poetry in general (6o6d), he issues an invitation to defend poetry (6o6e-6o8a), but states his provisional bottom line: one should avoid tragedy (6o8a-b). ${ }^{53}$

makes a desideratum of successful tragic imitation). It is also important that mixed pleasures of comedy involve conceiving of the ridiculous figure as a friend.

53 Alternatively, one can read him as saying that when we watch tragedy, we must rehearse these arguments as a charm against its corruptive effects—and presumably, we must not lament while watching (6o8a; cf. Jansen 2015).

PHRONESIS 61 (2016) 373-396 
This completes his account of the value of justice in this life independently of its actual reputation and rewards. So, he turns to the post-mortem value of justice, still considered independently of reputation and rewards (6o8c-612a). ${ }^{54}$ Finally, he returns the actual reputations and rewards of justice and injustice. First, he returns their actual reputation and rewards in this life, from gods $(612 \mathrm{e}-613 \mathrm{~b})$ and human beings (613b-e). Then he returns their post-mortem reputation and rewards (614a-621b). He concludes with an exhortation to virtue and justice $(621 b-c)$.

My reading of Socrates' second critique of poetry thus lets us see it as a key part of a systematic defense of his main thesis. His critique also serves the other functions ascribed to it-it returns to stories about human beings and integrates his discussion of poetry with subsequent metaphysical and psychological theorizing - but we need not appeal to such purposes to explain why Socrates talks about poetry at all. ${ }^{55} \mathrm{His}$ second critique of poetry is an integral part of his third, 'most decisive' argument for the value of justice, independent of reputation and rewards, within this lifetime. ${ }^{56}$

\section{References}

Adam, J. (1902) (ed.), The Republic of Plato. Cambridge.

Annas, J. (1982), 'Plato on the Triviality of Literature' in J. Moravcsik and P. Temko (eds.), Plato on Beauty, Wisdom, and the Arts (Totowa, NJ), 1-28.

Belfiore, E. (1983), 'Plato's Greatest Accusation against Poetry', Canadian Journal of Philosophy: Supplementary Volume 9: 39-62.

54 He proceeds by arguing that the soul—or reason, at least—is immortal. That bolsters the 'greatest and most decisive' argument as well; immortality of a pleasure's subject is one dimension of hedonic measurement at $585 \mathrm{a}$-e.

55 An anonymous referee worries that this may be too strong. Even if Socrates must discuss mixed pleasures within the soul to complete his larger discussion of hedonic error, that does not explain why he talks about the pleasures of poetry in particular. Perhaps so, but it is striking that Socrates makes the same choice in the Philebus, where he does not need to tie up any loose ends about poetry. (Of course, this does not yet explain why Plato emphasizes the pleasures of poetry in both works.)

$5^{6}$ I owe thanks to Julia Annas, Emily Austin, Sarah Jansen, Rachana Kamtekar and Rachel Singpurwalla for comments on earlier versions of this material. I also owe thanks to audiences at the APA Central (2014), the European Philosophical Society for the Study of Emotion (2015) and the Rocky Mountain Ethics Congress (2015). At the last of those events, Sam Shook presented comments and Mitzi Lee asked many questions and offered encouragement. Finally, I owe thanks to an anonymous referee for Phronesis for sound advice, only some of which I have been able to incorporate. 
Carroll, N. (1990), The Philosophy of Horror. New York.

Feagin, S. (1983), 'The Pleasures of Tragedy', American Philosophical Quarterly 20: 95-104.

Ferrari, G. R. F. (1989), 'Plato and Poetry' in G. Kennedy (ed.), The Cambridge History of Literary Criticism (Cambridge), 92-148.

Frede, D. (1993) (tr.), Plato: Philebus. Indianapolis.

Heath, M. (2013), Ancient Philosophical Poetics. Cambridge.

Irwin, T. (1977), 'Plato's Heracleiteanism', Philosophical Quarterly 27: 1-13.

Jansen, S. (2015), 'Audience Psychology and Censorship in Plato's Republic: The Problem of the Irrational Part', Epoche 19: 205-15.

Moss, J. (2007), 'What is Imitative Poetry and Why is it Bad?' in G. R. F. Ferrari (ed.), The Cambridge Companion to Plato's Republic (Cambridge), 415-44.

Nehamas, A. (1982), 'Plato on Imitation and Poetry in Republic 10' in J. Moravcsik and P. Temko (eds.), Plato on Beauty, Wisdom, and the Arts (Totowa, NJ), 47-78.

Reeve, C. D. C. (2004) (tr.), Plato: Republic. Indianapolis.

Sedley, D. N. (2013), 'Socratic Intellectualism in the Republic's Central Digression' in G. Boys-Stones, D. El Murr and C. Gill (eds.), The Platonic Art of Philosophy (Cambridge), 70-89.

Shaw, J. C. (2011), 'Socrates and the True Political Craft', Classical Philology 106: 187-207.

Shaw, J. C. (2015), Plato's Anti-Hedonism and the Protagoras. Cambridge.

Smuts, A. (2009), 'Art and Negative Affect', Philosophy Compass 4: 39-55.

Vlastos, G. (1973), 'The Individual as an Object of Love in Plato' in his Platonic Studies (Princeton), 3-34. 